\title{
治療に難渋したカンジダ性脊椎炎の一症例
}

\author{
大分県立病院整形外科 \\ 松林昌平・吉田伍一 \\ 渡 邊 精一郎・土井口 祐 一 \\ 鹿 島 信 之・山田 健 治
}

\section{A Report of a Difficult Case of Candida Spondylitis}

\author{
Shohei Matsubayashi, Goichi Yoshida, Seiichirou Watanabe \\ Yuuichi Doiguchi, Nobuyuki Kashima, and Kenji Yamada \\ Department of Orthopaedic Surgery, Oita Prefectural Hospital
}

\begin{abstract}
Recently, infections caused by Candida are increasing due to the increase in the compromised host. In this paper, we report a difficult case of Candida spondylitis.

A61 years old man had high fever and liver dysfunction. He underwent liver biopsy in the internal medicine division. He also underwent laparoscopic operation for removing the hematoma in surgery. Afterward CT showed abscess in iliopsoas and epidural, around lumbar vertebral. We performed needle biopsy. The cultures were positive for Candida albicans. Chemotherapy performed during ESR became normal after 4 weeks. Then spondylitis recurred. Chemotherapy had no effects this time. We operated with anterior decompression and bone grafts. Chemotherapy stopped after ESR became normal 12 weeks later Spondylitis has not recurred even now.

Generally chemotherapy continues after WBC, CRP and ESR become normal for 3 to 4 weeks. But difficult cases of Candida spondylitis need longer term chemotherapy.
\end{abstract}

Key words : Candida (カンジダ), spondylitis (春椎炎)

\section{はじめに}

真菌性脊椎炎は比較的希な疾患であるが, 近年, 抗 癌剤, 長期大量の抗生剂, ステロイド剤の使用によっ て生じる全身免疫力の低下を背景として, 真菌性脊椎 炎の増加傾向があるといわれている2)(5)10). 今回我々 は, 難治性のカンジダ性脊椎炎の一例を経験したので 報告する.

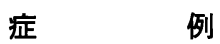

症例 : 61 歳, 男性.

主訴 : 発熱, 腰痛.

既往歴 : 特記事項なし。
現病歴 : 平成 8 年 7 月より断続的に熱発が持続し, 肝機能低下む出現したため，精查目的にて当院内科に 入院した，10月 23 日経皮的肝生検施行後，腹腔内出 血をきたしたため, 同日腹腔鏡下で凝血塊除去を行っ た。このとき硬膜外チューブを挿入している．11月 5 日 CT にて腸腰筋, 椎体周囲, 硬膜外に膿瘍を認め た。 エコーガイド下に腸腰筋膿瘍の経皮的穿刺を行い， 培養にて Candida albicans を検出した。化学療法を 開始して 6 ケ月後 CT にて膿場消失した。ささらに 2 ケ 月後血沈正常化が 4 週持続したことを確認して，化学 療法を中止したところ，再度熱発し春椎炎の診断で当 科入院した（表 1 ).

入院時現症：体温は $37.2^{\circ} \mathrm{C}$. 腰痛があり，右股関節 
表 1 当科入院前の治療経過

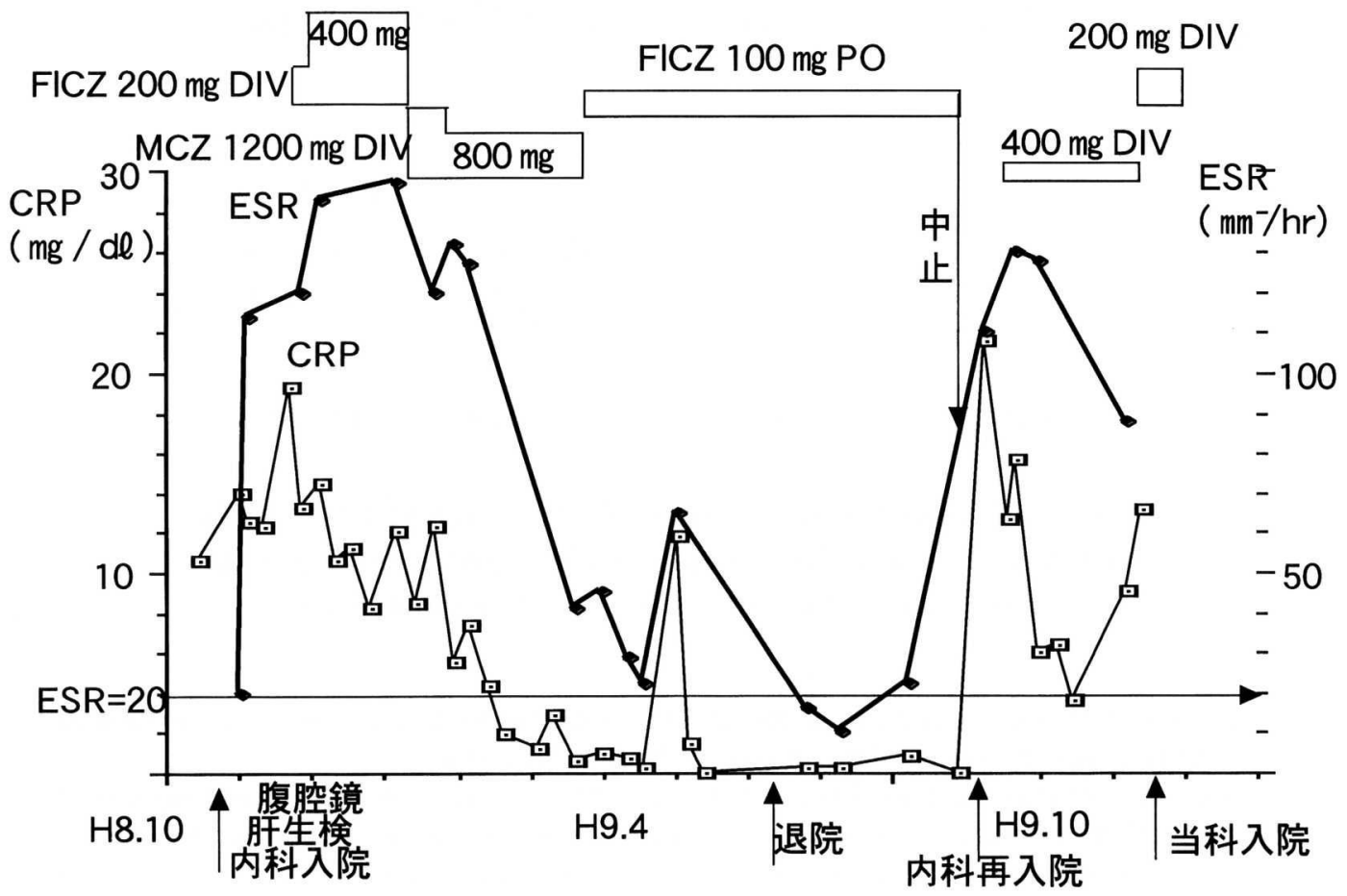

は屈曲位で，いわゆる腸腰筋肢位を呈していた．神経 学的所見で明らかな異常は無かった。

血液検查所見：WBC $7730 / \mathrm{ul}$, ESR $75 \mathrm{~mm} / 1$ 時 間, CRP $5.4 \mathrm{mg} / \mathrm{d} 1$ と炎症反応が陽性だった。他は 特に異常は無かった。

画像所見 : 単純X線像では L4/5, L5/S1 の椎間板 の狭小化と L4 から S1 にかけて骨破壊像が認められ （図 1)，骨シンチではL4 からS1にかけて，異常集 積像を認めた（図 $2 \mathrm{a}$ ). CT では両側の腸腰筋内に膿 瘍が認められた (図 $2 \mathrm{~b}$ ). MRI では L4 から S1 の椎 体の破壊像を認め, 造影では䍜患椎間板を囲むよう rim enhancement 認めた（図 3 ).

治療経過 : 手術は経腹膜的に椎体に到達した。両側 の腸腰筋内から約 $20 \mathrm{cc}$ の混濁した黄白色の膿を吸引 した. L4/5，L5/S1 の椎間板と椎体の一部を掻爬し， 骨移植を行った。 ギプスベッド上で 3 力月安静とし, その後硬性コルセットを装着した。入院の間フルコナ ゾール (FLCZ) とフルシトシン (5-FC) の 2 剂併 用投与を行い，退院後はフルコナゾール（FLCZ）の
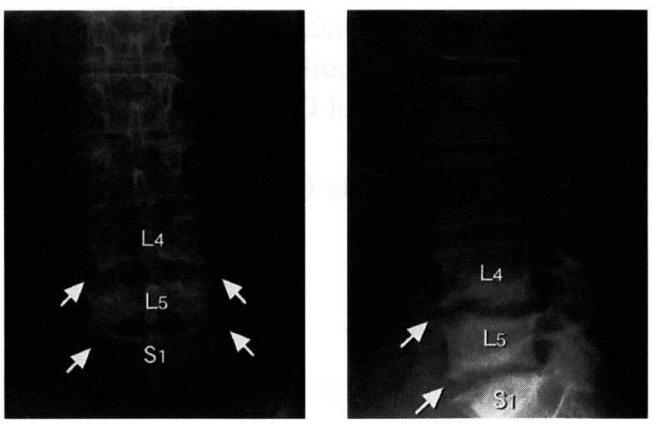

図 1 L4/5,L5/S1 の椎間板の狭小化. L4 から S1 にかけて骨破壊像を認めた。

単剤投与を行った. 血沈の正常化を約 12 週間確認し, 投薬を終了した（表 2 )。現在腰痛はなく，X線上も 移植骨生着し椎体は癒合した（図 4 ).

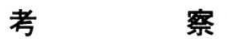

カンジダ性脊椎炎を含めた化膿性脊椎炎は保存療法 

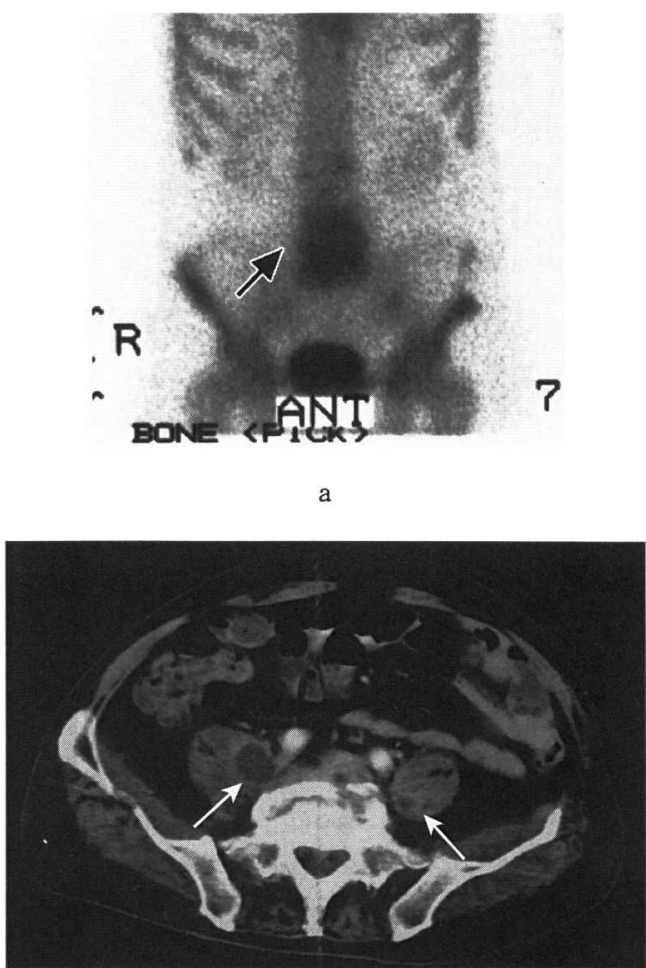

b

図 2 a L4 からS1にかけて異常集積像を認めた b 両側の腸腰筋内に膿瘍が認められた
が第一選択となるが, 進行性の神経脱落症状を有する 例, 骨破壊の進行する例, 脊椎アライメント不良例, 保存療法 $(4 \sim 8$ 週) にて炎症が鎮静化しない例や再 発を繰り返す例では手術適応と思われる ${ }^{1) 3)}$.

手術は病巣掻爬が基本であることから原則的には前 方固定術が施行される ${ }^{8)}$. その理由として, 病巣が血 行に乏しい腐骨や癒痕組織に覆われている場合, 全身 投与による化学療法では有効性が少なく，長期大量が 余儀なくされる.このことは必然的に耐性や副作用の 問題を引き起こす。そのため病巣に直達し感染組織や 㓔痕組織などを掻爬し，出血がみられる健常部まで露 出することは, 化学療法の効果を高めるためにも意義 があると思われる7?.

一般に抗真菌剤としては, アンホテリシンB (AMPH), フルシトシン $(5-\mathrm{FC})$, ミコナゾール $(\mathrm{MCZ})$, フル コナゾール (FLCZ)，イトラコナゾール (ITZ) の 5 種類があり, 一次選択薬としては, 殺菌性で耐性菌が 少なく効果の安定した AMPH が用いられるが5), AMPH は腎障害, 肝障書などの副作用が強くその使 用が限定される ${ }^{2)}$. そこで通常副作用が少なくカンジ ダ属に対して抗真菌活性の優れた FLCZ が用いられ る. また FLCZ と 5-FC の組み合わせで相乗効果が あり, FLCZ と AMPH の組み合わせで相加効果があ る $^{10)}$ と報告されているので, 今回我々は FLCZ と 5FC の二斉併用投与を行った。

化学療法の期間は，全身，局所所見が鎮静し，白血 球数正常，CRP 陰性となり，血沈が 1 時間值で 20 以
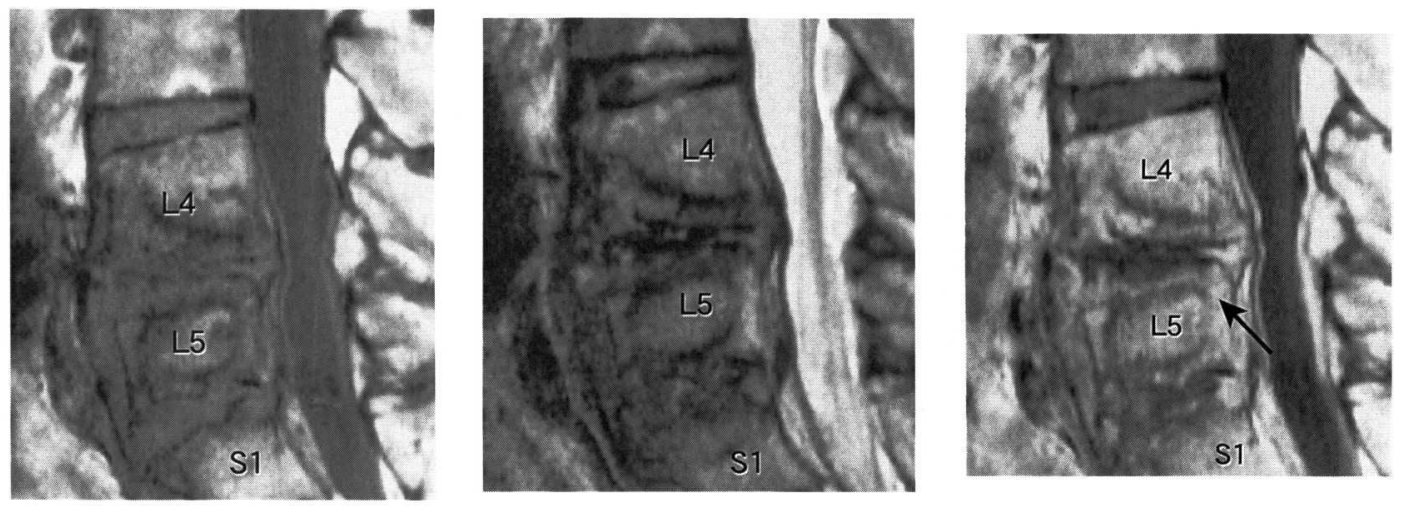

図 $3 \quad \mathrm{a}|\mathrm{b}| \mathrm{c}$

a T1 強調画像, b T2 強調画像, c 造影 $\mathrm{T} 1$ 強調画像

L4 から S1 の椎体の破壊像を認め造影では罹患椎間板を囲むように rim enhancement を認めた 
表 2 当科入院後の治療経過
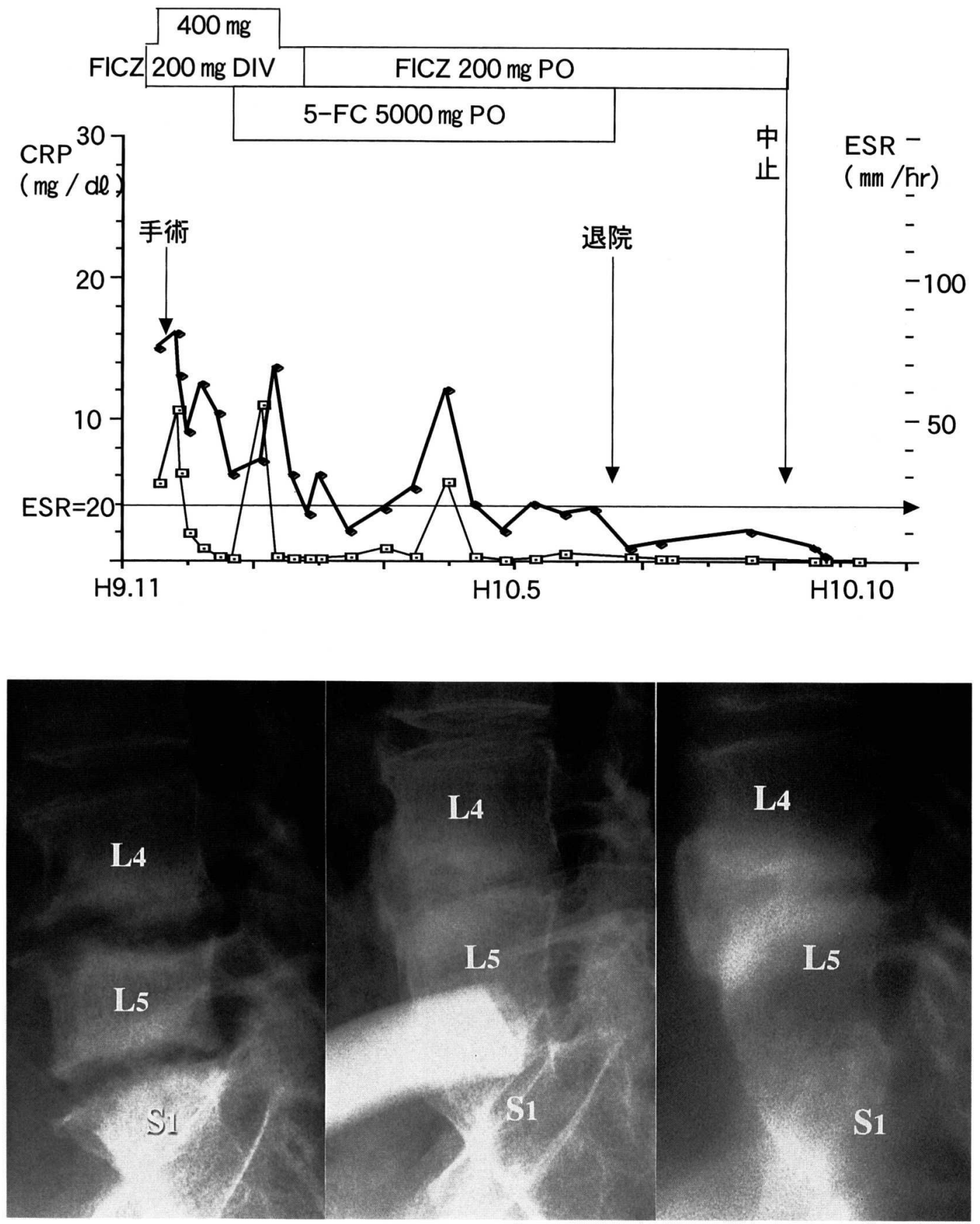

図4 a | b | c

a 術前単純 $\mathrm{X}$ 線像, $\mathrm{b}$ 術後単純 $\mathrm{X}$ 線像, $\mathrm{c}$ 術後断層 $\mathrm{X}$ 線像 移植骨生着し, 椎体癒合は完成している 
下が $3 \sim 4$ 週間続くまで ${ }^{6}$ が一般的だが, 年齢, 部位, 体重, 全身状態などの相違により変更するのが妥当で あり, 林 ${ }^{9)}$ は成人の急性の骨関節感染症で治癒判定後 4 週, 慢性で 8 週, 小児でその半分としている. 会田 ら ${ }^{1)}$ も化膿性脊椎炎の化学療法の期間を炎症所見が鎮 静化し, すべての検查成績が正常化後 3 力月間を目安 としていることょり, 今回の我々の二回目の化学療法 期間は適当と思われる。 また最近では，治瘉半定に MRI を利用することも検討されており，炎症所見が 陰性化した段階でもMRIで椎体, 椎間の輝度变化が 残存している症例もある ${ }^{4)}$ ので, 炎症所見が陰性化後 あさらに一定期間の化学療法が必要と思われる.

$$
\text { ま と め }
$$

治療に難渋したカンジダ性脊椎炎の一例を報告した. 難治性のカンジダ性脊椎炎では, 血沈が正常化後 12 週間の化学療法が有効だった。

\section{参 考 献}

1）会田育男ほか：脊椎感染症の薬物療法. 脊椎脊䯣 8 (9) 693-695, 1995

2）荒巻忠道ほか：カンジダによる腰椎椎間板炎の一例. 臨整外 25 （5）603-606, 1993.

3）池田天史ほか：当科における化膿性脊椎炎および結核 性脊椎炎の治療経験。整形外科之災害外科 46：（1） 102-104, 1997.

4）上ノ町重和ほか：化膿性脊椎炎の診断之治療. 整形外 科と災善外科 46 (1) $70-72,1997$.

5）小野俊明ほか：真菌による化膿性脊椎炎の治療. MB, Orthop 9: (6) 109-116, 1996.

6) 河路 渡 : 整形外科領域における感染症の診断と治療 日整会誌 $62 ， 1245-1256 ， 1988$.

7）佐藤栄修ほか：結核性脊椎炎に対する脊椎 instrumen-

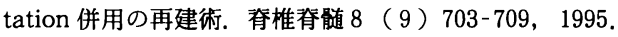

8）司馬 立ほか：化膿性脊椎炎の再建術。脊椎脊䯣 8 (9) 697-702, 1995.

9）林 浩一郎：骨関節感染症における抗生物質の使い方. 整形外科 36 (10) 1463-1468, 1985.

10）前崎繁文ほか：深左性真菌症の治療．診断と治療 81 (1) $101-108,1993$. 